\title{
SEASHORE TOURISM POLICY SELECTION AND LOCAL INHABITANT SATISFACTION EVALUATION BY TOPSIS METHOD
}

\author{
Kuo-Yan Wang, School of Economics and Management, Guangdong University of Petrochemical \\ Technology, Maoming, Guangdong, China \\ Jing Yu, School of Economics and Management, Guangdong University of Petrochemical Technology, \\ Maoming, Guangdong, China \\ Chia-Yang Ning, School of Economics and Management, Guangdong University of Petrochemical \\ Technology, Maoming, Guangdong, China
}

dx.doi.org/10.18374/JIMS-21-1.3

\begin{abstract}
Seashore tourism, especially in the seaside township, has rapidly developed in the recent years. In addition to fishing industry, the development of tourism activities has become an income-generating method for local economy. This empirical study illustrates how a seaside township selects a suitable tourism development solution using a simple group decision making method of TOPSIS. The attitudes of the inhabitants were surveyed in regards towards the costal tourism stimulus package implemented for half of a year. The discussions derived from the results can be used as a reference to promote the usefulness of seashore tourism and regional economic development at the township level, as well as to properly respond to the needs of inhabitants.
\end{abstract}

Keywords: Seashore tourism, Inhabitant satisfaction, solution assessment, decision-making process 